\title{
Lavender Oil
}

National Cancer Institute

\section{Source}

National Cancer Institute. Lavender Oil. NCI Thesaurus. Code C66002.

The essential oil extracted from the flowers of several species of Lavandula. Lavender oil is used primarily for its aromatic properties in parfumery, aromatherapy, skincare products, and other consumer products. 